Ronald D Seegobin MRCP FFARCS, Gillian $L$ van Hasselt FFARCs

\title{
Aspiration beyond endotracheal cuffs
}

Large-volume low-pressure cuffs have been introduced in an endeavour to reduce the incidence of tracheal mucosal damage. These cuffs when inflated to clinical seal develop folds, which together with low clinical seal pressure may not protect against aspiration.

This study compares the incidence of aspiration of dye past a variety of large-volume cuffed tubes and red rubber low-volume cuffs inflated to clinical seal in a group of 30 patients.

The incidence of dye tracking past the large-volume cuffs studies was 100 per cent whereas no aspiration of dye was seen past the red rubber tubes.

Increasing cuff pressure in the large-volume cuffs beyond clinical seal to $50 \mathrm{~cm} \mathrm{H}_{2} \mathrm{O}$ did not obliterate the dye-filled cuff folds, despite wide variation in the thickness of the cuff material.

The introduction of large-volume low-pressure cuffs has sought to reduce the incidence of tracheal mucosal damage due to excessive transmitted tracheal wall pressure. The theory of action of large volume cuffs has been described by Carrol et al. ${ }^{1}$ Major manufacturers have produced large-volume cuffs to achieve a cuff system whereby clinical seal is achieved below capillary perfusion pressures.

Endotracheal tubes with these large-volume cuffs have cuff diameters ranging from 1.5 to 2 times the diameter of the average adult male trachea. Thus they necessarily develop folds in the cuffs when placed in the trachea and inflated to achieve clinical

\section{Key words}

EQUIPMENT: endotracheal tubes, endotracheal tube cuffs; COMPLICATIONS: aspiration.

From The Shakleton Department of Anaesthesia, Southampton General Hospital, Southampton.

Address correspondence to: Dr. R.D. Seegobin, Chaleur Regional Hospital, Postal Drawer " $S$ ", Bathurst, New Brunswick, Canada E2A 4A4. seal. These folds, coupled with the low clinical seal pressure characteristic of these tubes may not protect against the aspiration of liquid pharyngeal contents. ${ }^{2}$ It has been suggested that a pressure of at least $25 \mathrm{~cm} \mathrm{H} \mathrm{H}_{2} \mathrm{O}$ in the cuff system is needed to prevent aspiration past the endotracheal tube. ${ }^{3}$

This study arose from incidental observations made during work looking at the effect of transmitted cuff pressure using large-volume cuffs on mucosal blood flow. The consistent observation was made of excessive folding of cuff material, with sputum tracking down these folds. ${ }^{4}$ Thus the present study was designed to look at the incidence of aspiration of liquid contents beyond large volume cuffed tubes inflated to $25 \mathrm{~cm} \mathrm{H}_{2} \mathrm{O}$ intracuff pressure, and further to define a safe pressure. The study also sought to compare aspiration past a variety of large-volume cuffed tubes and red rubber lowvolume cuffs inflated to clinical seal.

\section{Methods}

Thirty adult patients undergoing surgery requiring the use of an endotracheal tube and muscle relaxation as part of the anaesthetic technique, after giving their informed consent, were admitted to the study, which was approved by the local ethical committee.

Patients were allocated, using a suitable table of random numbers, to have either a plastic largevolume cuffed tube (size $8 \mathrm{~mm}$ ID for women, size $9 \mathrm{~mm}$ ID for men). The large-volume cuffed tubes assessed were the Portex Profile, Mallinkrodt HiLo, and Lanz endotracheal tubes.

All patients received a premedicaton of diazepam $10 \mathrm{mg}$ and metaclopramide $10 \mathrm{mg}$ orally two hours preoperatively. Anaesthesia was induced with thiopentone $3.5 \mathrm{mg} \cdot \mathrm{kg}^{-1}$, and intubation performed $3 \mathrm{~min}$ after alcuronium $0.3 \mathrm{mg} \cdot \mathrm{kg}^{-1}$. Anaesthesia was maintained with a mixture of nitrous oxide and oxygen in $2: 1$ ratio, fentanyl $1 \mu \mathrm{g} \cdot \mathrm{kg}^{-1}$ at induction and $0.25 \mu \mathrm{g} \cdot \mathrm{kg}^{-1}$ at half-hourly intervals thereafter. Ventilation was achieved using a Manley ventilator with the fresh gas flow adjusted to 


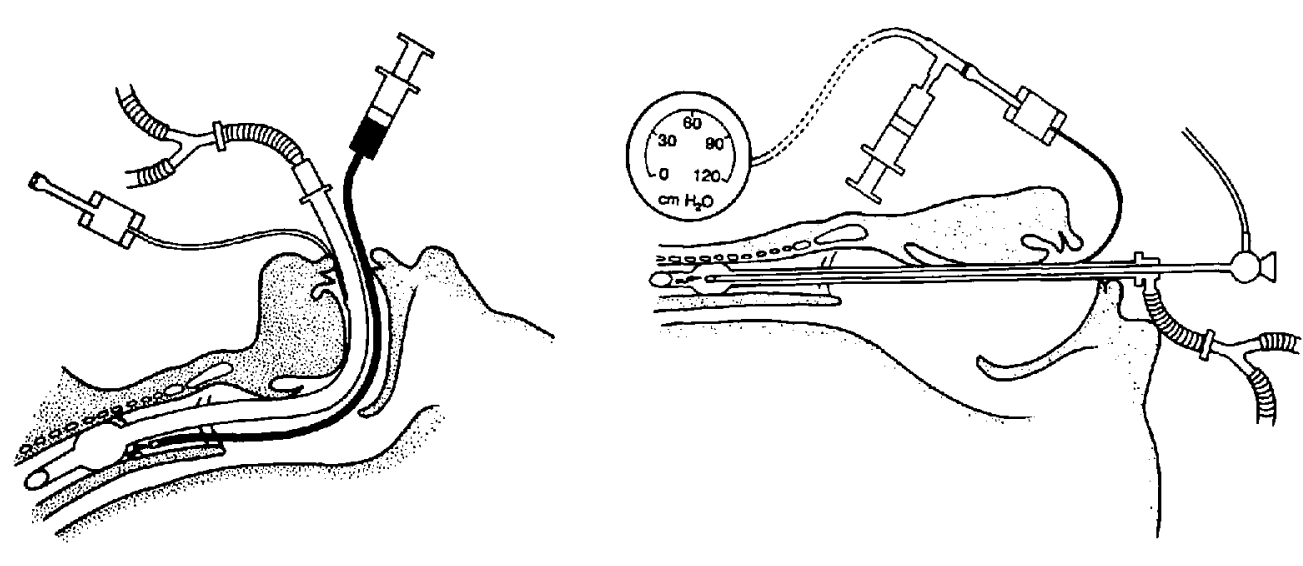

FIGURE I Schematic representation of technique.

achieve a tidal volume of $10 \mathrm{ml} \cdot \mathrm{kg}^{-1}$ and a rate of 12 cycles/minute.

In the case of the red rubber tubes, the cuff was inflated using air to "clinical seal," judged by the cessation of audible leak around the cuff, and checked by auscultation with a stethoscope over the larynx.

The clear tube large-volume cuffs specially provided by Portex and Mallinkrodt but identical in all other respects to the standard endotracheal tubes were first evacuated, then inflated using sterile normal saline to a pressure of $25 \mathrm{~cm} \mathrm{H}_{2} \mathrm{O}$. The Lanz tube was inflated until the pilot balloon was half filled and the pressure of the system then measured using a Smith gauge, previously calibrated using a water column. Saline was used for cuff inflation to minimise light reflection from the inner cuff wall.

After each intubation and inflation of the endotracheal tube cuff, $2 \mathrm{ml}$ of indocyanine green dye were instilled through the cords immediately above the cuff using a plastic quill (Figure 1). At the end of the operation, before reversal of paralysis, a rigid fibreoptic right angled bronchoscope was passed and the incidence of dye aspiration via the folds noted for each large cuffed tube and photographically documented as previously described, ${ }^{4}$ using an Olympus OM2 camera with a Wolf $85-105 \mathrm{~mm}$ lens and an AMI photographic light source. The Portex Profile, and Mallinkdrodt Hi-Lo tubes were then inflated to a pressure of $50 \mathrm{~cm} \mathrm{H}_{2} \mathrm{O}$, and the effect of the dye-filled folds was noted.

In those patients intubated with red rubber tubes, the trachea below the endotracheal tube was inspected for the presence of dye.

After use, each disposable cuff was washed clean, and the cuff cut into $1 \mathrm{~cm}$ wide strips. Mid cuff material thickness was measured using a Moore and Wright metric micrometer.

\section{Results}

The Table summarizes the incidence of passage of dye beyond the cuffed tubes. Figures 2 and 3 show

TABLE Cuff characteristics and incidence of aspiration

\begin{tabular}{|c|c|c|c|c|}
\hline Tube & Red rubber & Portex profile & Mallinkrodt & Lanz \\
\hline Number of patients & 15 & 5 & 5 & 5 \\
\hline End point of inflation & Clinical seal & $25 \mathrm{~cm} \mathrm{H}_{2} \mathrm{O}$ & $25 \mathrm{~cm} \mathrm{H}_{2} \mathrm{O}$ & $27 \pm 2 \mathrm{~cm} \mathrm{H}_{2} \mathrm{O}$ \\
\hline Male & 7 & 2 & 2 & 5 \\
\hline Female & 8 & 3 & 3 & 0 \\
\hline Aspiration & $0 / 15$ & $5 / 5$ & $5 / 5$ & $5 / 5$ \\
\hline Average mid-cuff thickness (mm) & N/A & 0.13 & 0.06 & 0.06 \\
\hline
\end{tabular}



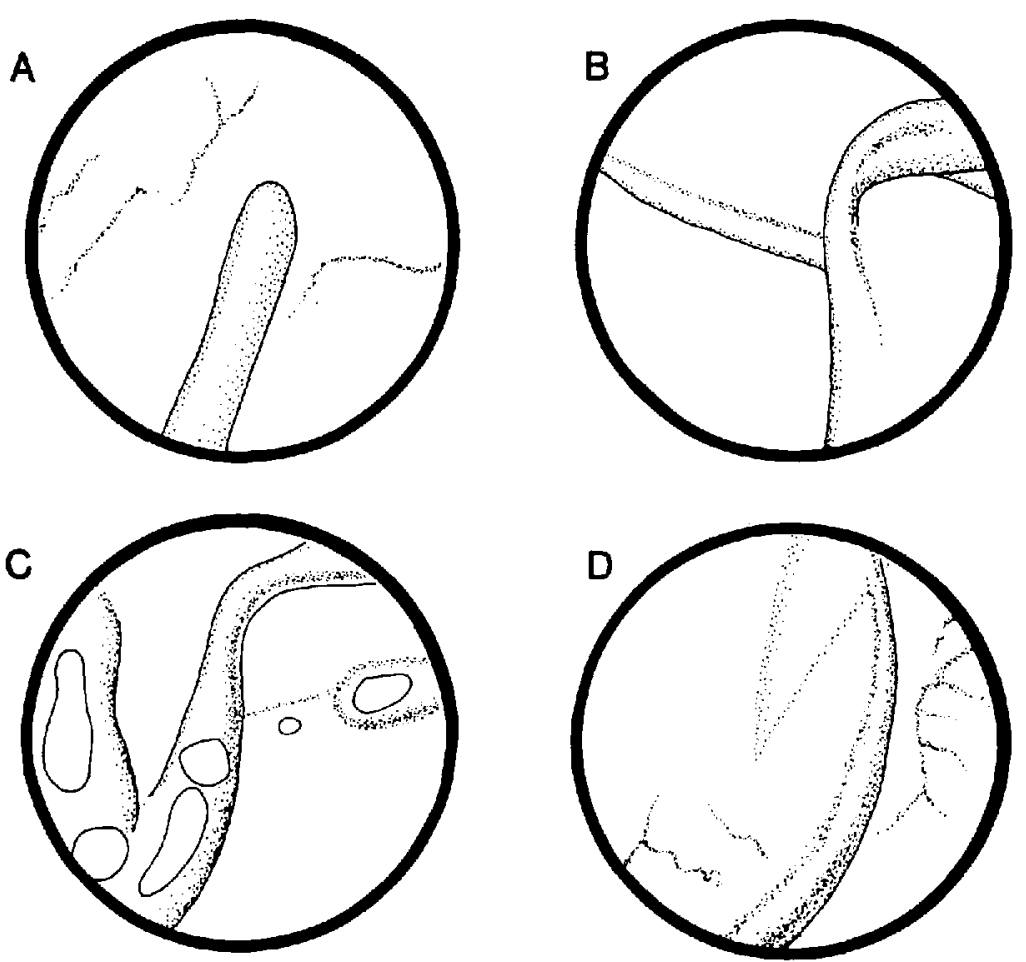

FIGURE 2 Illustration of typical random folds

$A=$ blind ending fold $; B+D=$ random folds; $C=$ secretion filled folds.

the folds typically seen in a large-volume cuff at an inflating pressure of $25 \mathrm{~cm} \mathrm{H}_{2} \mathrm{O}$. Secretions and air bubbles are seen in the folds. The pattern of folding is random. Some folds end before traversing the length of the cuff.

No dye passed beyond the red rubber cuffed tubes. Dye passed beyond all of the large volume cuffed tubes and this passage was clearly related to the channels formed by the excess cuff material (Figures 4, 5).

The Lanz tube with its pressure limiting device could not be pressurised to $50 \mathrm{~cm} \mathrm{H}_{2} \mathrm{O}$. The mid-cuff thickness of the Mallinkrodt and Lanz tubes was half that of the Portex tubes (Table). Inflating the cuffs of the Portex and Mallinkrodt tubes to a pressure of $50 \mathrm{~cm} \mathrm{H}_{2} \mathrm{O}$ did not obliterate the dye filled folds, and dye could be seen tracking along the folds.

\section{Discussion}

The airways of patients are at risk from regurgitation during general anaesthesia. The frequency of hiatus hernia in the general population varies with age. In one series of patients presenting for routine barium meal, 5 the incidence ranged from nine per cent in patients below age 40 , to 69 per cent in patients over 70 (overall incidence 29.6 per cent). Thirty-eight per cent of patients with symptomless hiatus hernia showed evidence of concurrent gastrooesophageal reflux.

Turndorf et al., ${ }^{6}$ found an overall incidence of silent regurgitation of 14.5 per cent of patients during general anaesthesia. Regurgitation was significantly greater in prone patients and those having upper abdominal procedures, and if a relaxant, narcotic, and $\mathrm{N}_{2} \mathrm{O}: \mathrm{O}_{2}$ intermittent positive pressure ventilation technique was used. 

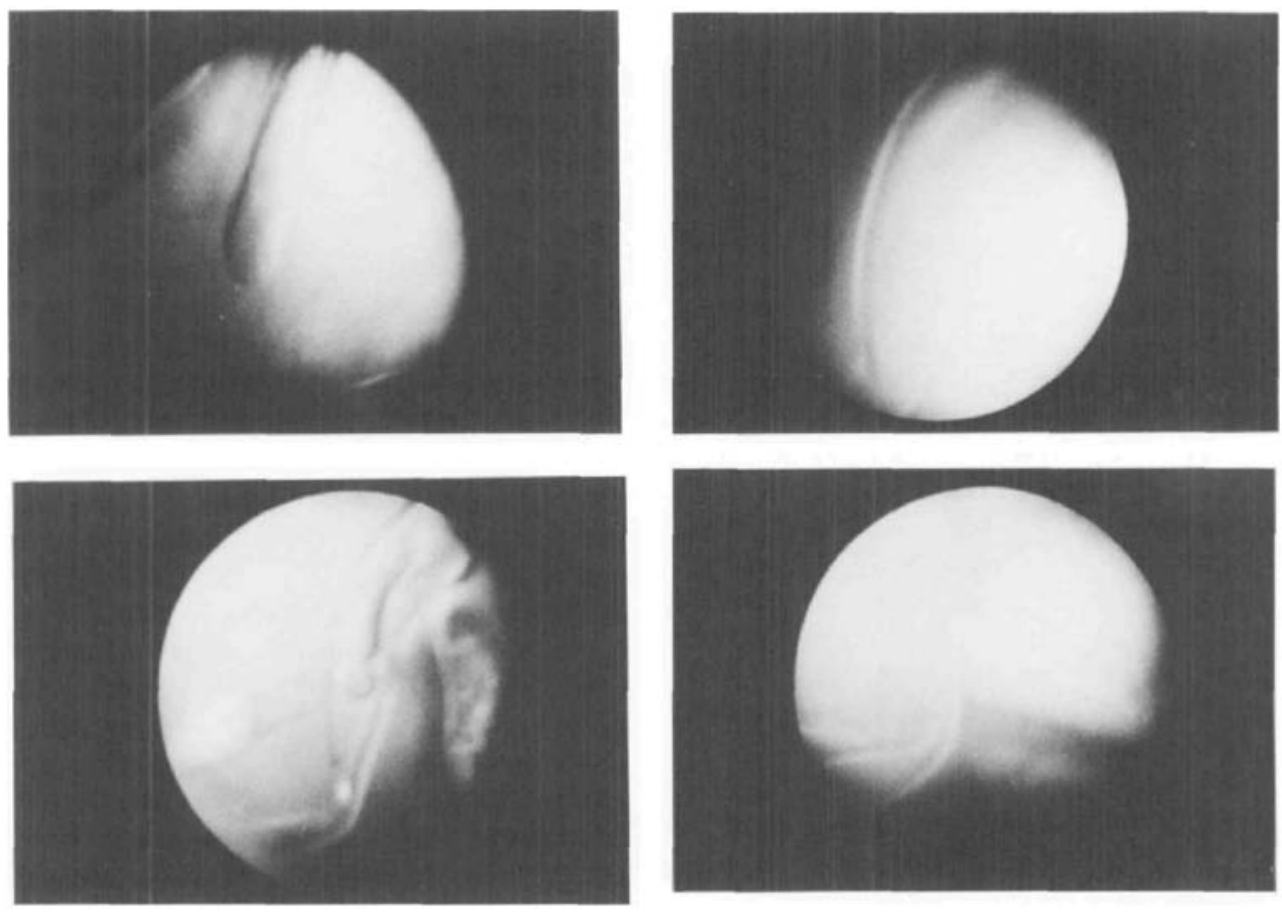

FIGURE 3 Photographs showing typical random folds.

Top left blind-ending fold; top and bottom right random folds; bottom left secretion-filled folds.

Under general anaesthesia, and in cases requiring prolonged intubation, cuffed endotracheal tubes are used to control and protect the airway. Both low volume cuffed red rubber tubes, and large volume cuffed tubes are widely used.

The incidence of aspiration beyond low volume, high pressure cuffs will be a function of their method of use. Bernhard et al. ${ }^{3}$ found no evidence of aspiration when these low volume cuffs were inflated to clinical seal. In contrast Spray et al. ${ }^{7}$ found a 56 per cent incidence of aspiration in patients intubated with low volume cuffed tubes, though the end point of cuff inflation is not stated. If these cuffs are inflated to minimal leak as proposed by Homi et al..$^{8}$ to minimise the damage due to high lateral wall pressure, then aspiration may well occur. In our study the red rubber low-volume cuffs were all inflated to clinical seal, and like Bernhard et $a .^{3}{ }^{3}$ we found no aspiration. However, it must be remembered that at clinical seal, such tubes generate a lateral wall pressure of $68 \mathrm{~cm} \mathrm{H} \mathrm{H}_{2} \mathrm{O}$ or greater. ${ }^{9,10}$ Mucosal blood flow is totally obstructed over cartilagenous rings at $50 \mathrm{~cm} \mathrm{H}_{2} \mathrm{O}$ pressure. ${ }^{4}$

Lateral wall pressure generated by the endotracheal cuff is thought to be the most important factor in tracheal morbidity due to intubation with cuffed endotracheal tubes. ${ }^{11}$ Large volume cuffs were designed to achieve clinical seal at low intracuff pressures. Their use has reduced the incidence of tracheal morbidity in patients undergoing long-term ventilation. In view of the high lateral wall pressures generated by red rubber tubes at clinical seal, it has been proposed that large volume tubes should be used for all procedures requiring intubation. ${ }^{9}$

The characteristics of these large-volume cuffs with cuff diameters exceeding that of the trachea by 50-100 per cent is such that folding of redundant cuff material occurs at clinical seal. The thickness 

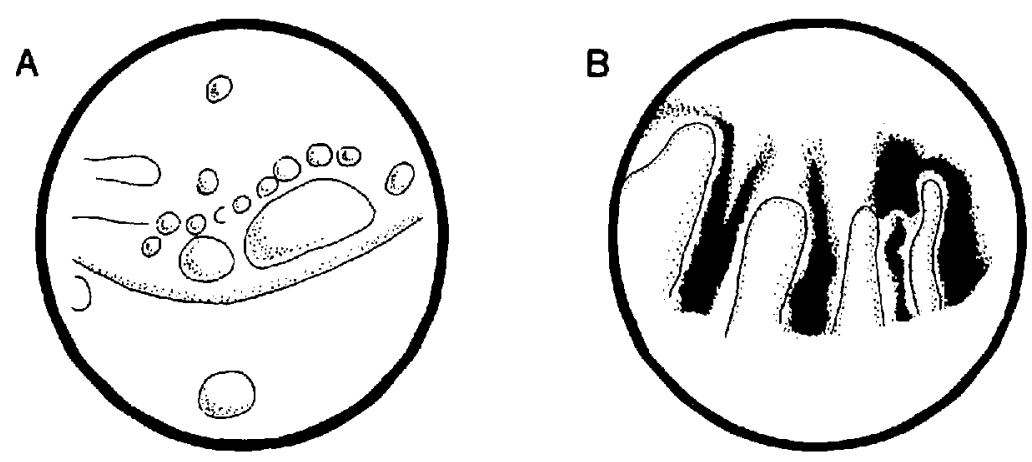

C
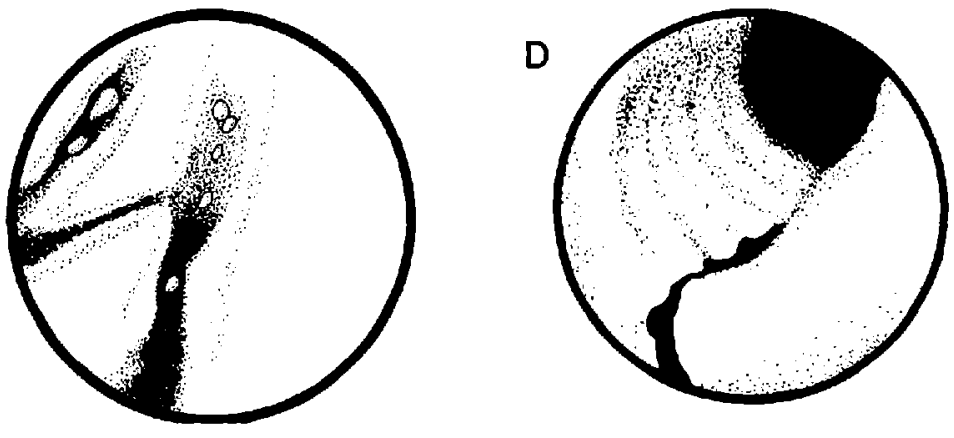

FIGURE 4 Illustration of aspiration of dye

$A=$ random folds with secretions; $B=$ dye tracking down folds; $C=$ dye in folds; $D=$ dye in trachea beyond cuff.

of cuff material may prevent the obliteration of folds as cuff pressure increases.

The incidence of aspiration beyond large volume cuffs also varies. Spray et $a l^{7}$ found an aspiration rate with large-volume cuffs of 20-29 per cent. Bernhard et al.$^{3}$ found a 38 per cent aspiration rate using large thin walled cuffs at intracuff pressures of $20 \mathrm{~cm} \mathrm{H}_{2} \mathrm{O}$. In both studies no aspiration was found when intracuff pressure was $25 \mathrm{~cm} \mathrm{H}_{2} \mathrm{O}$ or greater.

This study differs from those of Bernhard et al. ${ }^{3}$ and Spray et al. ${ }^{7}$ by showing 100 per cent aspiration with the large volume cuffs investigated. A cuff pressure of $50 \mathrm{~cm} \mathrm{H} \mathrm{H}_{2} \mathrm{O}$ did not occlude the channels of such aspiration. This may be due to three factors: - No antisialogogue was used in the premedication of patients in our series. Incidental secretions in the mouth and trachea are greater in the presence of an endotracheal tube.

- No lubricant jelly was applied to the cuffs of these tubes to facilitate intubation. This jelly coupled with antisialogogue premedication may well decrease aspiration in two ways. The jelly may fill the folds. Reduced pharyngotracheal secretions and altered mucosal ciliary motility may delay the dissolution of such lubricant.

- Dye in this study was not placed in the oropharynx as in earlier studies, but beyond the vocal cords and above the inflated cuff. This ensured the placement of dye immediately above the folds in the cuff material.

It has been proposed that thinner cuff materials result in folds that are easily obliterated by a rise in cuff pressure. ${ }^{3}$ Inflating the Mallinkrodt Hi-Lo and 

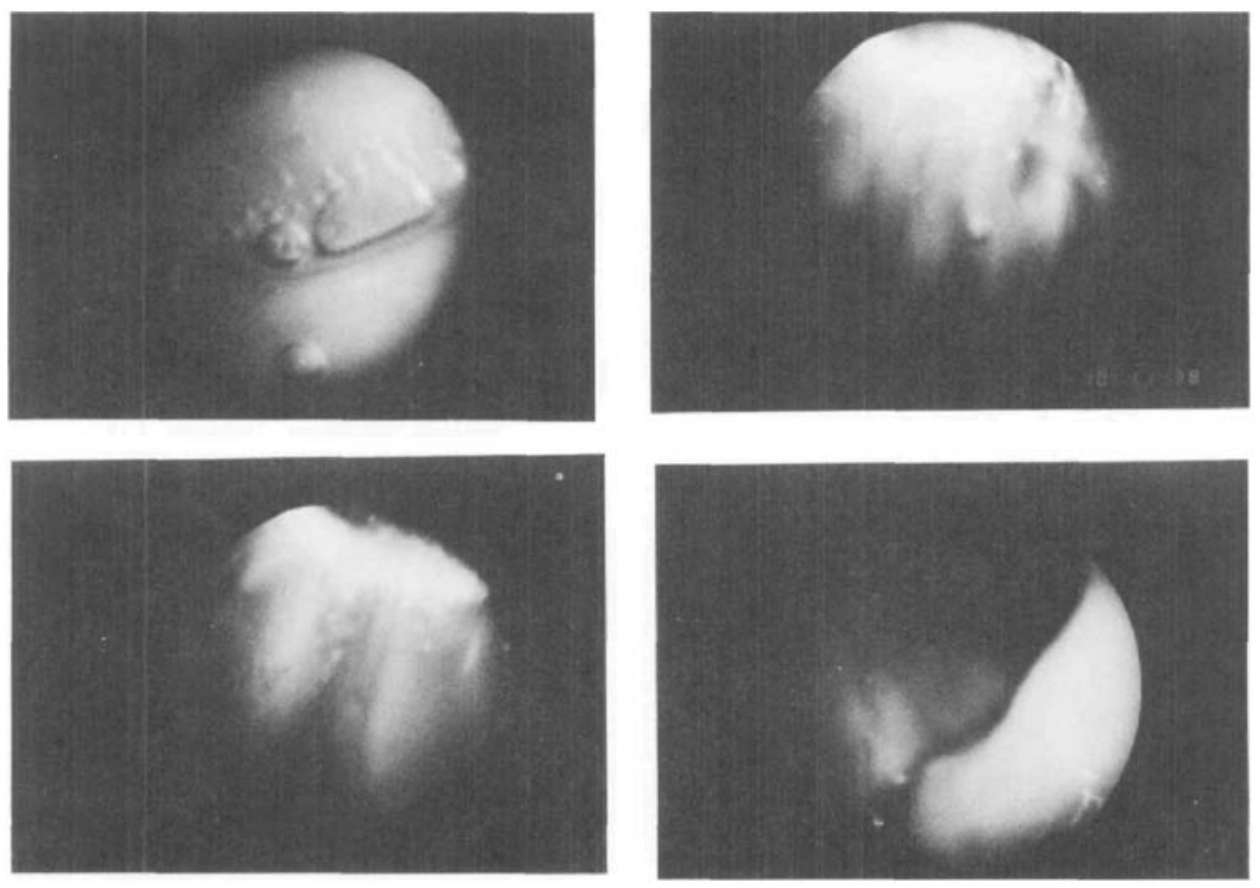

FIGURE 5 Photographs showing aspiration of dye.

Top left random folds with secretions; top right dye tracking down folds; bottom left dye in folds; bottom right dye in trachea beyond cuff.

Portex Profile cuffs to $50 \mathrm{~cm} \mathrm{H}_{2} \mathrm{O}$ did not obliterate the dye-filled folds, despite a two-fold difference in the thickness of the respective cuff materials.

A pharynx full of liquid contents should exert a head of pressure no greater than $20 \mathrm{~cm} \mathrm{H}_{2} \mathrm{O} .{ }^{12}$ Our earlier study ${ }^{4}$ has shown that using large volume cuffs, an intracuff pressure greater than $30 \mathrm{~cm} \mathrm{H}_{2} \mathrm{O}$ impairs tracheal mucosal blood flow. This flow becomes obstructed between 40 and $50 \mathrm{~cm} \mathrm{H}_{2} \mathrm{O}$. Such intracuff pressures did not compress the folds seen in that study, despite similar variation in cuff material thickness.

Passage of dye in this study beyond the largevolume cuffed tubes can clearly be shown to be related to the folds created by excess cuff material. These folds are not obliterated by cuff pressures in excess of that intracuff pressure which will compromise tracheal mucosal blood flow. The pressure required to compress these folds may be more related to the elasticity of the cuff material than to cuff material thickness.

The ease of passage of liquids along the folds in large-volume cuffed endotracheal tubes will depend on the viscosity of the liquid above the cuffed tube. ${ }^{2}$ Whereas protection may be afforded against the ingression of solid material, surface tension forces and capillary action may ensure that liquids will track along the folds despite increased intracuff pressures. Such a mechanism would explain aspiration despite the minimal volume of dye placed above the cuffs. In this study intermittent positive pressure ventilation was used. The potential for aspiration will be increased in spontaneously breathing intubated patients.

The clinical significance of these findings needs further evaluation. A wide range of patients including those with pre-existing respiratory disease may be adversely affected. Patients with prolonged 
gastrointestinal obstruction presenting for surgery and patients in the intensive care unit undergoing prolonged intubation and ventilation are at particular risk. In such patients, either alteration of gastric acidity due to antacid therapy or cimetidine, ${ }^{13}$ or systemic antibiotic therapy, ${ }^{14}$ can lead to significant colonisation of the stomach with atypical gram negative organisms with subsequent pneumonia with identical organisms. Du Moulin et al. ${ }^{13}$ found a 51 per cent incidence of such sequential pneumonia in a series of 60 patients 58 of whom required positive pressure ventilation, though it is not stated what type of endotracheal tube was used. The design of large-volume cuffed endotracheal tubes, whilst ensuring a safe lateral wall pressure if carefully inflated, may in at risk patients, facilitate further respiratory complications by nature of their design.

To accommodate variations in tracheal anatomy, and changes in tracheal tone, the residual volume of the ideal endotracheal cuff should be slightly less than the diameter of the trachea, with plasticity in cuff material sufficient to achieve a ten per cent increase in cuff diameter over the range of inflating pressure 20 to $30 \mathrm{~cm} \mathrm{H} \mathrm{H}_{2} \mathrm{O}$. Such characteristics should avoid cuff folding, accommodate variations in tracheal size and ensure seal at a lateral pressure which does not compromise tracheal mucosal blood flow. The search for such an ideal tube and its performance are the subject of further studies.

\section{References}

1 Carroll RG, McGinnis GE, Grenvik A. Performance characteristics of tracheal cuffs. International Anesthesiology Clinics, 1974; 12: 111-31.

2 Pavlin EG, Van Nimwegan D, Hornbein TF.

Failure of a high compliance low pressure cuff to prevent aspiration. Anesthesiology, 1975; 42: 216-9.

3 Bernhard WN, Cottrell JE, Sivakumaran O, Patel K, Yost $L$, Turndorf $H$. Adjustment of intracuff pressure to prevent aspiration. Anesthesiology, 1979; 50: 363-6.

4 Seegobin RD, van Hasselt GL. Endotracheal cuff pressure and tracheal mucosal blood flow: endoscopic study of effects of four large volume cuffs. $\mathrm{Br}$ Med J, 1984; 288: 965-8.

5 Pridie $R B$. Incidence and coincidence of hiatus hernia. Gut, 1966; 7: 188-9.

6 Turndorf H, Rodis ID, Clark TS. "Silent" regurgita- tion during general anesthesia. Anesth Analg. 1974; 53: $700-3$.

7 Spray SB, Zuidema GD, Cameron JL. Aspiration pneumonia: incidence of aspiration with endotracheal tubes. Am J Surg 1976; 131: 701-3.

8 Homi J, Notcutt W, Jones JJ, Sparks BR. A method for comparing endotracheal cuffs. Br J Anaesth 1978; 50: 435-45.

9 Leigh JM, Maynard JP. Pressure on the tracheal mucosa from cuffed tubes. Br Med J 1979; 1 : 1173-4.

10 Black AMS, Seegobin RD. Pressures on endotracheal cuffs. Anaesthesia, 1981; 36: 498-511.

$11 \operatorname{Nordin} N$. The trachea and cuff induced tracheal injury. An experimental study on causative factors and prevention. Acta Otolaryngology, 1976; 345: 1-71.

12 Metha S. Safe lateral wall pressure to prevent aspiration. Ann R Coll Surg Engl 1984; 66: 426-7.

13 Du Moulin GC, Patterson DG. Hedley-Whyte J, Lisbon A. Aspiration of gastric bacteria in antacid treated patients: a frequent cause of post-operative colonisation of the airway. Lancet 1982; 1: 242-5.

14 Stoutenbeek ChP, Van Saene HKF, Miranda DR, Zandstra DF, Binnendijk $B$. The prevention of superinfection in multiple trauma patients. J Antimicrob Chemotherapy. 1984; 14: Suppl. B 203-211.

\section{Résumé}

Les ballonnets à basse pression et grand volume ont été introduits afin de diminuer l'incidence des lésions de la muqueuse trachéale. Ces ballonnets quand gonflés afin d'assurer un étanchéité clinique peuvent développer des plicatures qui accompagnées d' une pression d'occlusion basse peuvent ne pas protéger contre l'aspiration.

Cette étude compare l'incidence de l'aspiration de colorant à travers une variété de ballonnets à large volume et les ballonnets à petit volume en caoutchouc rouge gonfles afin d' assurer l'étanchéité clinique dans un groupe de 30 patients.

L'incidence de colorant trouvée au delà des ballonnets à large volume était de 100 pour cent alors qu'aucune aspiration de colorant n'a été vue au delà des ballonnets à faible volume de tube endotrachéal en caoutchouc rouge.

L'augmentation de la pression dans le ballonnet des tubes endotrachéaux d̀ gros volume jusqu' à $50 \mathrm{~cm} \mathrm{H} \mathrm{H}_{2} \mathrm{O}$ $n$ 'a pas diminué la plicature de ces ballonnets malgré les variations énormes dans l'épaisseur du matériel de ces ballonnets. 